$\xi=-1$

\title{
Glimpses Of Dynamic Biodiesel Product Pricing Model
}

\author{
Zakir Hussain ${ }^{1}$, Deepa Meghavathu², Rakesh Kumar ${ }^{1 *}$ \\ ${ }^{I}$ Department of Chemical Engineering, Rajiv Gandhi Institute of Petroleum Technology, Jais, Amethi-229304, Uttar Pradesh, India. \\ ${ }^{2}$ Department of Chemical Engineering, Andhra University College of Engineering, Visakhapatnam-530003, Andhra Pradesh, India. \\ *Corresponding author Email: rkumar@rgipt.ac.in
}

\begin{abstract}
Entrepreneurship development, energy crisis, rising fossil fuel prices, increasing greenhouse gas emission and waste management are the key issues which concern the government to tackle them sustainably. The advent of biodiesel as a fuel paves the pathway to handle these issues and together it creates an opportunity to develop a small/medium to large-scale biodiesel production units. Current research is mainly focused on creating the roadmap to solve the feedstock scarcity issue faced by Indian biodiesel industries through the field survey. It also presents a robust model framework to fix the minimum selling price of biodiesel through energy input-output and cost inputout analysis in producing a unit volume of biodiesel. The results show that the surveyed area may have the potential to supply on an average of 129 liters/day waste vegetable oil. Energy analysis shows that the highest share of energy $71.84 \%$ was from waste vegetable oil followed by $25.99 \%$ corresponds to alcohol. Others are being at $0.85 \%$ due to the catalyst, $0.44 \%$ due to electricity, $0.68 \%$ due to machinery and $0.2 \%$ due to human labor. Cost analysis shows that the highest share of cost $52.13 \%$ was due to alcohol followed by $39.34 \%$ due to waste cooking oil.
\end{abstract}

Keywords: Biodiesel; Esterification; Energy \& Cost analysis; Product pricing; Transesterification.

\section{Introduction}

Sustainable governance is the responsibility of both federal \& state governments. It lies in tackling the major issues like entrepreneurship development, energy crisis, rising fossil fuel prices, increasing greenhouse gas emission, increasing air and water pollution \& waste management[1-5]. These issues are importan globally and require an immediate attention through local resource management approach[6]. The government of India is no exemption to tackle these issues with a good \& profound philosophy.

The advent of biofuel particularly biodiesel as a fuel is proven to tackle these issues with an optimum maneuver[7]. Moreover, biodiesel production technology through non-edible \& waste oils is the proven milestone in the course of biofuel development $[8,9]$. Biodiesel is technically a modified form of glycerides present in the vegetable oils and shows the fueling properties very similar to that of fossil-derived diesel[10]. Biodiesel is environmentally friendly oil, clean-burning fuel derived only from the renewable sources, usage of it can lower the greenhouse gas emission from $57-86 \%[11]$. Moreover, it is biodegradable in nature[12,13].

There is a huge demand for biodiesel and so there is a great demand for raw materials too. Different sources and their potentials in generating waste vegetable oils and its supply chain management are not usually practiced in India[11]. Quantification of waste vegetable oil generating potential sources in India is a needed attention.

In spite of no available data on the quantified raw material at our disposal, India is also lacking behind the clear pricing policy for biodiesel. Moreover, studies on energy and cost analysis of biodiesel production in India is also not available. The current research tries to address these gaps and proposes the following objectives using novel research theme presented in Fig. 1.
The first objective of the current research is to gauge the potential of various entities in Rae Bareli city, Uttar Pradesh in generating waste vegetable oil. It is expected that this type of data is most useful for the biodiesel plants primarily that the general trends developed from the survey results can be used in business planning and decision making.

The second objective is to obtain energy and cost parameters by simulating a biodiesel production process through non-catalytic esterification route coupled with a conventional transesterification. This type of approach is of great importance in reporting the technical viability of the production process.

The third objective is to conduct energy and cost analysis of biodiesel production. This can form the basis to frame the biodiesel product pricing in contrast to its feedstock \& technology related costs. This type of studies is the main building block to set the solid dynamic biodiesel product pricing policy.

\section{Methodology}

\subsection{Field survey}

The survey to quantify the waste vegetable oil generating capacity of various entities in Rae Bareli city was conceived on the weekends of February-April of 2016. The geographical area in which the survey has been carried out lies between latitude $25^{\circ} 49^{\prime}$ North and $26^{\circ} 36^{\prime}$ North and longitude $100^{\circ} 41^{\prime}$ East and $81^{\circ} 34^{\prime}$ East. Queries were asked in-person to each enterprise like

1. How much of waste oil on an average be generated in a day operation?

2. Do you have any deep fryers \& then how many?

3. What type of oil do you use?

4. What do you do with the waste oil?

5. Would you like to involve in local biodiesel initiative? 
6. Are you willing to sell the waste oil?

7. Would you like to donate the waste oil?

8. At what price do you want to sell the waste oil?

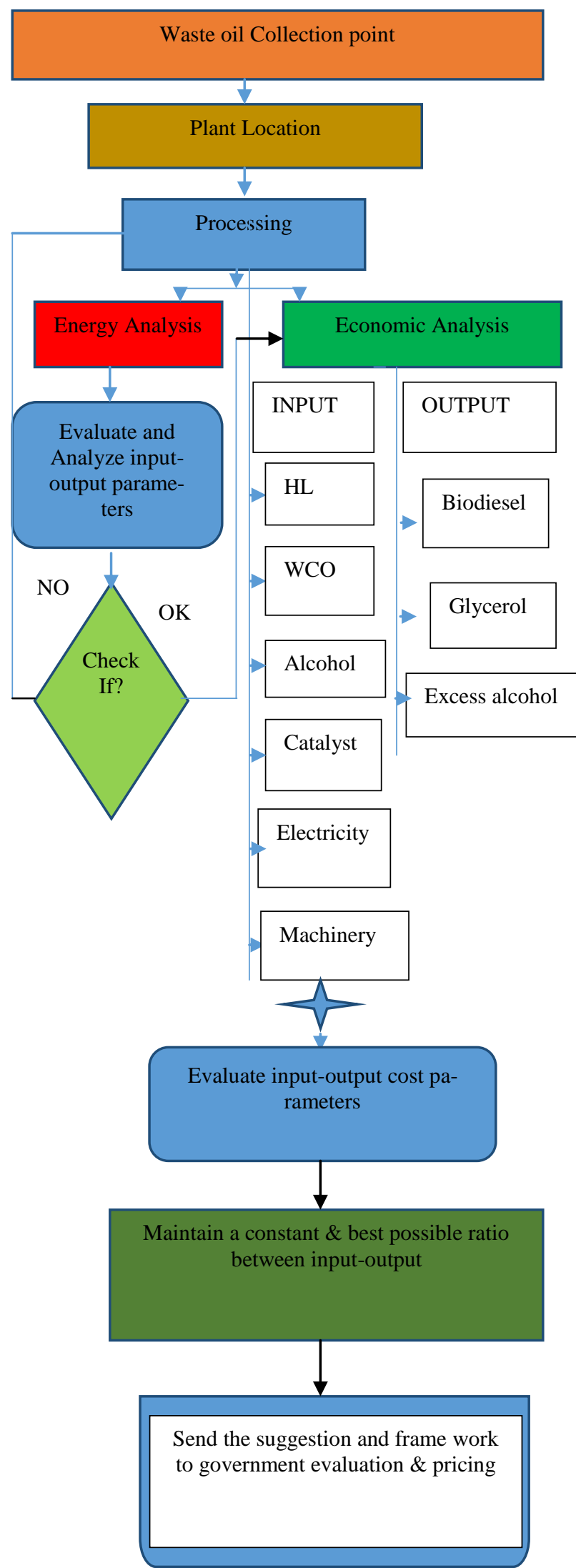

Fig. 1: Dynamic biodiesel product pricing model

\subsection{Simulation}

Aspen plus software (ver. 8.6) was used to simulate both esterification and transesterification processes. RCSTR module was used for both the reactions. Other equipment's and utilities like flash column, heat exchanger, cooler, and mixer were used for esterification. Whereas, for transesterification Rstoic, radfrac, wash column, filter, pump, mixers \& heat exchanges were used. These equipment's and other utilities are interconnected with each other according to their requirement. Process conditions are maintained in accordance with the experimental results. A new esterification process at high temperature \& pressure through non-catalyst route were employed here, because of its ease of separation of esterified product. The energy and cost input-output parameters are taken from the simulated process flow sheet.

\section{Results \& discussions}

\subsection{Field report}

An exclusive field survey has been carried out to gauge the potential of various entities in Rae Bareli city in generating the waste vegetable oil on a daily basis. The adverse effect of using recycled oils frequently was explained to the management. In brief, the following process of fragmentation and its effects were explained: Vegetable oils are the main and major source of nutrients in our daily food intake and nourishment. With an increase in the frequency of reuse of oil renders it to be toxic at some point in time when consumed. During the frying cycle, the triglycerides in vegetable oils get fragmented to free fatty acids. When oil with high free fatty acid content is used in food supplements will show an adverse effect on human health like insulin resistance and thereby cause inflammation and obesity[14]. In brief, in the frying process of vegetable oils, FFA content increases with increase in the frequency of frying cycles.

The detailed mechanism of fragmentation is as follows:

When food is deep-fried in heated oil (depending on the food being fried), the moisture forms steam, which evaporates with an effervescent action and gradually sinks. Water and oxygen initiate the chemical reaction between oil and food. Water, being a weak nucleophile (donor of electron pair), attacks or hydrolyzes the organic compound linkage of triglycerides and produces di- and monoglycerides, glycerol along with FFA.

We have contacted the 22 identified potential restaurants, out of which 3 are the pure vegetarian and pizza making restaurants. They are having a waste oil generation capacity ranging from 2-15 liters per day, which they are disposing of as cattle feed; poultry feed, as cleaning agents for steel and iron pipes, to kill the woodeating beetles, emergency lamping. Some of them are claiming that their workers take away the waste oil to reuse in their home and very often they will throw away the oil. All the members claim to use sunflower, rice bran, canola, peanut oils. Surprisingly no one of them is using palm oil in the frying.

Analyzing all the survey results it can be affirmed that there is a possibility that 129 liters/day of waste vegetable oil can be collected if proper supply chain management technique is applied and negotiated well with the restaurant management. From this analysis, it can be concluded that Rae Bareli city will be the ideal location to start biodiesel plant initially of 129 liters/day capacity. Moreover, if the mixed feed biodiesel processing technique is adopted then the capacity can be further enhanced as per the feed oil supply.

If the researchers working in the area of biodiesel production can conduct a local survey on the availability of oil they are reporting in their publications, then there will be an overall global survey report at some point in time. This type of surveys can be a useful tool in order to strategically improve the biodiesel policy. Moreover, it can explore the biodiesel production possibilities from various available potential oil sources for a large scale supply, rather 
than producing biodiesel from less available or more costly oils which will have more commercial value elsewhere. As shown in Fig. 2 the two feasible collection points can be suggested based on the results. One point is at Ratapur Chauraha and another point is at Saras hotel (civil lines chauraha).

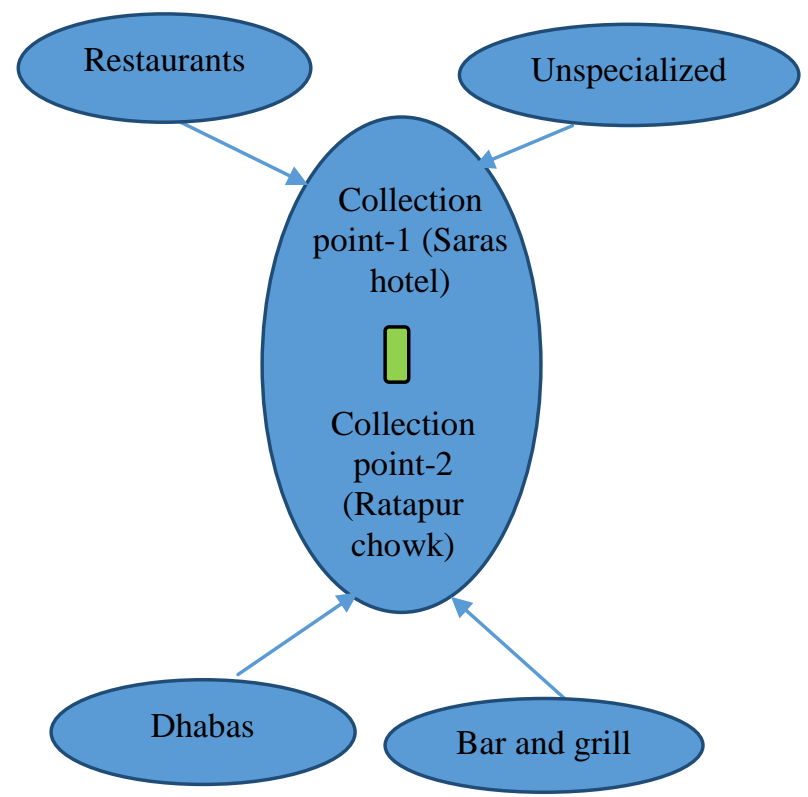

Fig. 2: Effect of catalyst type on biodiesel yield

\subsection{Analysis of input-output energy \& cost in biodiesel production}

Energy analysis was carried out using the input quantities of each head require to produce the unit volume of biodiesel and their corresponding output is gauged. The human labor requirement was taken from the work of (Mohammadshirazi et al.)[15]. Whereas, 1:7.5 oil to methanol molar ratio were used as input along with $1.5 \mathrm{wt} \%$ catalyst and yield of $97.126 \%$ based on the experimental results of our previous publication[9]. It was found that the highest share of energy $71.84 \%$ was due to waste vegetable (cooking) oil followed by $25.99 \%$ corresponds to alcohol. Others are being at $0.85 \%$ catalyst, $0.44 \%$ electricity, $0.68 \%$ machinery and $0.2 \%$ human labor as shown in Fig. 3.
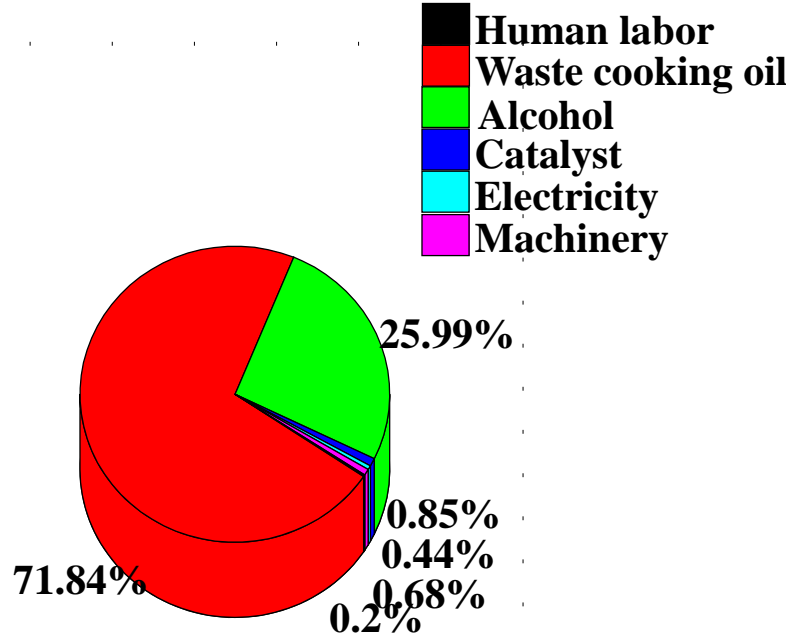

Fig.3: Shares of different forms of input energies in biodiesel production

From cost analysis, it was found that the highest share of cost $52.13 \%$ was due to alcohol followed by $39.34 \%$ was due to waste cooking oil as shown in the Fig.4. This shows that the methanol cost in India is very high. The net profit from the sale of biodiesel after substituting all the costs involved in the production was found to be Rs. 5.680 .

The study carried out in Iran by (Mohammadshirazi et al.)[15], reported the higher cost $54.81 \%$ was due to waste vegetable oil and the second higher cost was accounted for labor with $27.75 \%$. This difference in two studies is due to the fact that in their estimates they have used 1:4.8 oil: methanol molar ratio against 1: 7.5 molar ratio in the present study. According to Phan \& Phan[12], the best ratio to yield the highest amount of biodiesel is 1:7.5 oil to methanol molar ratio.

India is presently importing the methanol from Israel and is also a second largest importer of methanol after China. If enough methanol or bio-methanol is produced in India with the view to promote biodiesel, then there will be a possibility to avail methanol at a cheaper price.

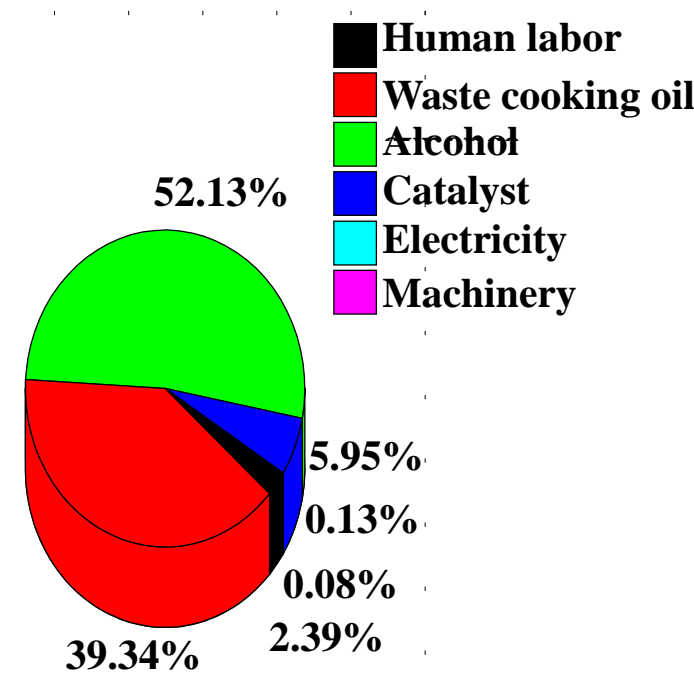

Fig.4: Distribution of input expenses in biodiesel production

\section{Conclusion \& managerial implications}

1. Based on the survey results the projected waste vegetable oil generation capacity is $129 \mathrm{~L} /$ day in Rae Bareli city. Some of the restaurant's management is interested in taking the local biodiesel generation initiative.

2. Process simulation shows that the non-catalytic esterification can also be carried out in a technically viable and economically feasible route as no extra heat duty is required to separate the esterified product.

3. Energy analysis result shows that there is a net positive energy, which means the biodiesel production through the current route is feasible.

4. Economic analysis of the production also shows a positive trait, despite low net profit.

5. The strong government policy for the collection of waste vegetable oils alike practiced in the European countries should come up along with the dynamic biodiesel product pricing policy.

\section{Acknowledgment}

We would like to acknowledge the Rajiv Gandhi Institute of Petroleum Technology (RGIPT), Jais, India for providing the facilities \& financial support for this work.

\section{References}

[1] Chhetri AB., Watts K. \& Islam MR (2008), Waste Cooking Oil as an Alternate Feedstock for Biodiesel Production. Energies 1, 3-18. doi:10.3390/en1010003. 
[2] Haider MB., Hussain Z \& Kumar R (2016), CO2 absorption and kinetic study in ionic liquid amine blends. Journal of Molecular Liquids 224, 1025-1031. doi:10.1016/j.molliq.2016.10.044.

[3] Bandary B, Hussain Z \& Kumar R (2016), Effect of carbon and nitrogen sources on Escherichia coli bacteria in removing dyes. Materials Today: Proceedings 3, 4023-4028. doi:10.1016/j.matpr.2016.11.067.

[4] Modi M, Ramchandra VP, Liyakhath ASk, Hussain Z (2013), A Review on Theoritical Air Pollutants Dispersion Models. International Journal of Pharmaceutical, Chemical and Biological Sciences 3, 1224-1230.

[5] Bandary B, Hussain Z \& King P (2016), Experimental study on non sporulating Escherichia Coli bacteria in removing methylene blue. International Journal of Pharma and Bio Sciences 7, B629-B637.

[6] Tsai, WT, Lin CC \& Yeh CW (2007), An analysis of biodiesel fuel from waste edible oil in Taiwan. Renewable and Sustainable Energy Reviews 11, (2007) 838-857. doi:10.1016/j.rser.2005.05.005.

[7] Demirbas A, (2009), Progress and recent trends in biodiesel fuels, Energy Conversion and Management 50, 14-34. doi:10.1016/j.enconman.2008.09.001.

[8] Devi KG., Meghavathu D, Velluri S, Mehtha CC \& Hussain Z (2015), Qualitative production of biodiesel using waste vegetable oil. Journal on Future Engineering \& Technology 10, (2015) 1-11.

[9] Hussain Z, Haider MB \& Kumar R (2016), UsageSpecific Biodiesel Production with and without catalytic booster. Materials Today: Proceedings 3, 4115-4120. doi:10.1016/j.matpr.2016.11.083.

[10] Zhao H \& Baker GA (2013), Ionic liquids and deep eutectic solvents for biodiesel synthesis: A review. Journal of Chemical Technology and Biotechnology 88, 3-12. doi:10.1002/jctb.3935.

[11] Singh SP \& Singh D (2010). Biodiesel production through the use of different sources and characterization of oils and their esters as the substitute of diesel: A review. Renewable and Sustainable Energy Reviews 14, 200-216. doi:10.1016/j.rser.2009.07.017.

[12] Phan AN \& Phan TM, (2008), Biodiesel production from waste cooking oils. Fuel 87, 3490-3496. doi:10.1016/j.fuel.2008.07.008.

[13] Axelsson L, Franzén M, Ostwald M, Berndes G, Lakshmi G Ravindranath NH (2012), Perspective: Jatropha cultivation in southern India: Assessing farmers' experiences. Biofuels, Bioproducts and Biorefining 6, 246-256. doi:10.1002/bbb.

[14] Karpe F, Dickmann JR \& Frayn KN (2011), Fatty acids, obesity, and insulin resistance: Time for a reevaluation. Diabetes 60, 24412449. doi:10.2337/db11-0425.

[15] Mohammadshirazi A, Akram A, Rafiee S, Bagheri KE (2014), Energy and cost analyses of biodiesel production from waste cooking oil. Renewable and Sustainable Energy Reviews 33, 44-49. doi:10.1016/j.rser.2014.01.067. 